\title{
Improvement of the Design Quality of 3D-Input Devices Using Motion Analyses and Biomechanical Comparisons
}

\author{
Tobias Nowack ${ }^{2}$, Stefan Lutherdt ${ }^{1}$, Manuel Möller ${ }^{1}$, Peter Kurtz ${ }^{2}$, and Hartmut Witte ${ }^{1}$ \\ ${ }^{1}$ Ilmenau University of Technology, Dept. of Biomechatronics, Ilmenau \\ ${ }^{2}$ Ilmenau University of Technology, Dept. of Working Sciences, Ilmenau \\ PF 1005 65, 98684 Ilmenau, Germany \\ tobias.nowack@tu-ilmenau.de, stefan.lutherdtatu-ilmenau.de, \\ peter.kurtz@tu-ilmenau.de, hartmut.witte@tu-ilmenau.de
}

\begin{abstract}
Due to the lack of investigations and standards describing the design of real 3D input devices a real 3D input device was develop. To compare several devices a test task was created and performed with combination of a motion capturing system. During the experiment 19 attendees with different levels of experience performed the test with this setup. Several intra-individual motion patterns and using strategies belonging to different input devices could be observed.
\end{abstract}

Keywords: User-centred design, 3D-input, evaluation software, reachable space of motion, ergonomically motivated equipment, motion analyses of input tasks.

\section{Introduction and Motivation}

International standard DIN ISO 9241-400 (last version 2007) describes principles and requirements for physical input devices. One of these principles is to minimize biomechanical strains, but there is no explanation how to reach this goal. Typically input devices (and in our case 3D-input devices as well) are evaluated during the stage of development by different usability test methods, like questionnaire-based test tasks. These predominately subjective evaluations indicate physical strain of the hand-armshoulder-system to be very high. But no simple relation to the objective parameters describing usability (course accuracy and handling time) could be identified [1]

Our hand is a tool adapted to "manipulation", a multitude of functions, most of which yet are even unknown, but not optimized for "indirect" manipulation of computer devices. But in a lot of industrial applications it is necessary to use indirect manipulations due to "wrong" size (too big or too small), dangerous environmental conditions or security aspects which provokes a few diverse discrepancies. Thus for industrially used machines it is necessary to have a control by human computer interfaces, does mean brain-hand-computer interfaces, where functions of brain and hand are coupled in mostly (yet) unknown manner. Present input devices for such interfaces restrict movements of the hand in comparison with direct manipulation, and in contrast to common 3D-use of hands. These restrictions force to develop attitudes of usage which never are comfortable or ergonomically. 
In 2007 the International Standard on "Ergonomics of human-machine-interaction Part 400: Principles and requirements for physical input devices" (ISO 9241-400) had been published as well as "Part 410: Design criteria for physical input devices" (ISO 9241-410). In these documents only generic ergonomic principles are given without any kind of data or evaluation criteria [3]. For 1D and 2D input devices literature gives good advices how the device should be constructed (see [4]). Krauss in 2003 [5] published an evaluation concept for 2D pointing devices.

During the last years several tests have been created to measure usability aspects of input devices with more than 2 input dimensions. One of these tests used at Ilmenau University of Technology is a migration of Krauss' tests tasks from 2D to 3D environments [6]. This test has been developed on the basic usability criteria "effectiveness, efficiency and satisfaction".

Within these experiments applied to the as well in Ilmenau developed 3D input device "Haptor" [7] several tests were performed. The results of these first studies are based on questionnaires and subjective impressions. Only time to solve the tasks (duration) could be objectified. After first tests it becomes obvious that it is necessary to measure more parameters than demanded by the basic test tasks. Therefore we extended the setup to measure motions and current positions of input devices, to allow to compare them kinematically.

\section{Description of Experiments}

\subsection{Test Equipment and Setup}

All experiments were executed in a laboratory protected against physical and psychological disturbances by other people, noise, machines or mechanical systems. The only confounder besides the presence of measuring systems was the laboratory temperature, because during winter time we were not able to securely assure living room temperature.

The measuring system used was a passive infrared motion capturing system called ProReflex from Swedish company Qualisys ${ }^{\circledR} A B$. This system consists of 6 IRcameras, IR-reflecting (passive) spherical markers and a laptop with the measuring software necessary to record and analyze motion data. The software used for recording was Qualisys Track Manager (QTM version 1.9.254). Analyzes also were made with QTM, with Microsoft ${ }^{\circledR}$ Excel2007, with SPSS v.14 and Matlab ${ }^{\circledR}$ R2007b.

Fig. 1. shows the whole setup with the used hardware components, without experimentees and test executives.

The above-mentioned test setup was prepared and tested for this special task within a pre-test stage over several months before the experiments started. During this time all influences of the system by the laboratory were minimized; the setup was adjusted, tested and finally recorded to ensure the reproducibility of the setup in later stages of (re-)experiments. 


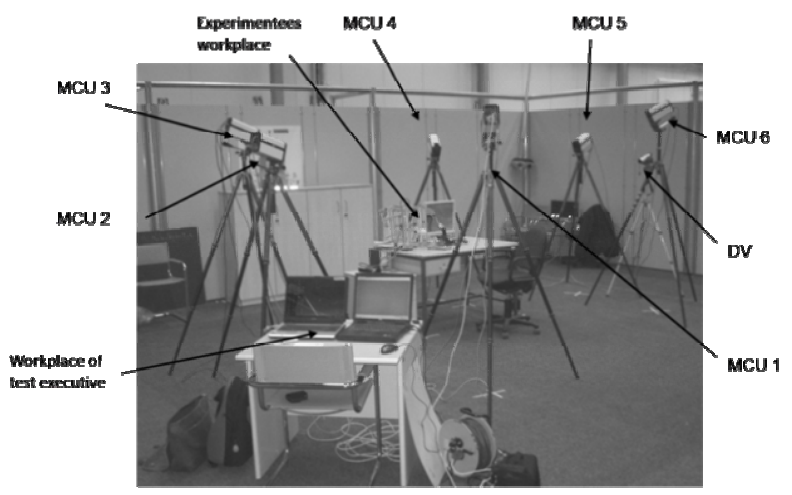

Fig. 1. Test setup for motion analyses with Qualisys ${ }^{\circledR}$ ProReflex

\subsection{Objects of Investigation}

During the tests the motions and motion ranges used by the utilization of three different input devices for the same standardized input task was investigated. These input devices were two market available pseudo 3D input devices: a gamepad from Hama and a joystick from Saitek (see fig. 2a and 2b). They are called "pseudo-3D" because only two axes are controllable at the same by one hand and one input action; the third axis had to be controlled by the other hand via an additional input element (a second mini-joystick and a throttle). Normally the gamepad is able to control 6 DOF (joystick 5 DOF), but ever only two dimensions at the same time. Both devices are angle based, but the test software generates a test task in which only the dead stop in each direction and the central position is necessary to be used. Therefore both devices can be compared with the Haptor as (discretely) "translation based" input devices.

In the gamepad input device, $\mathrm{x}$ - and $\mathrm{y}$-axes can be simultaneously controlled by the right mini joystick; z-axis has to be controlled by left mini joystick. Both joysticks are self-resetting to their initial central position by small springs. These springs impresses a light force which is not perceivable during use. The design of this gamepad (and others) is so that the user has only one way to hold and use it: with both hands and the thumbs forming input elements. The kind of use (hands-free, partially or totally propped) was not dictated and could be changed during the test too.

In Saitek's joystick the big shaft was used to control x- and y-axes and the throttle for z-axis. The small knob at the top is also a mini joystick but was not used in tests. The shaft is self-resetting to the initial center position by a spring, and this center position is well perceivable. The throttle has no perceivable position and is not selfresetting. The attendees could not use the joystick with their preferred hand because the necessity of controlling the throttle with the left hand (thumb or two fingers). The position on the table was not fixed; therewith the attendees could adjust the distance between them and the device to their physical needs. 
a)

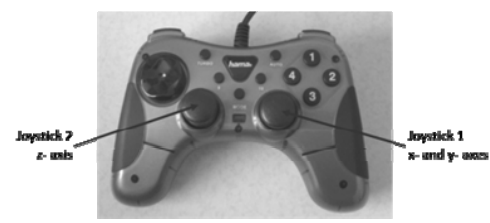

a) Hama PC Gamepad Greystorm

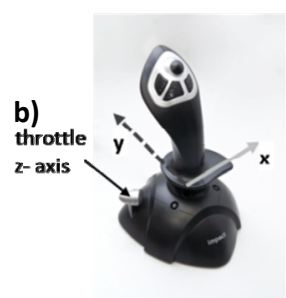

b) Saitek Impact X7-33U (ST30)

Fig. 2. Input devices tested

The third input device investigated was a prototype of the self-developed real 3D input device called Haptor, from the Dept. of Working Sciences of the Ilmenau University of Technology (see fig. 3). All axes at this device can be controlled by one hand at the same time. The additional throttle function (for speed acceleration) of arm rest was not used during these tests. The grip (and therewith the coupling point between human and machine) is represented by a ball. All three axes are not selfresetting and have no perceivable center position. Irrespective to the handiness, all the attendees had to use their left hand for input actions.

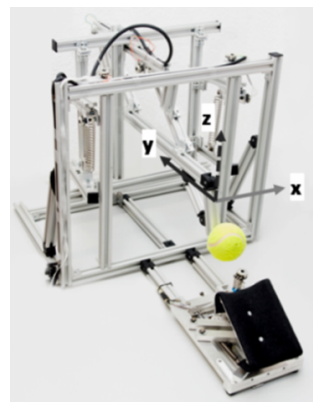

Fig. 3. Self-developed Haptor (Dept. of Working Sciences, TU Ilmenau) [7]

\subsection{Test Software and Test Tasks Performed}

To allow a standardization of the tests and to make the results comparable the experimentees had to perform a software given test task (see fig. 4). During this test they had to approach several goals marked by red dots. The current position was marked by green dots, and the whole test space was a cube with an edge length of 1024 pixel. The test consists of nine subtasks formed by translations from start via eight defined points to stop (which was equal to start position, for the whole test task see Tab. 1). The time to solve the test task was not restricted, but measured as "duration". The test software writes a log file with a timestamp (in milliseconds), the position in $\mathrm{x}-, \mathrm{y}-$ and z-coordinates (increments) and a marker "ze" for "goal reached". These data have been written to file whenever new data were available at the USB interface. 


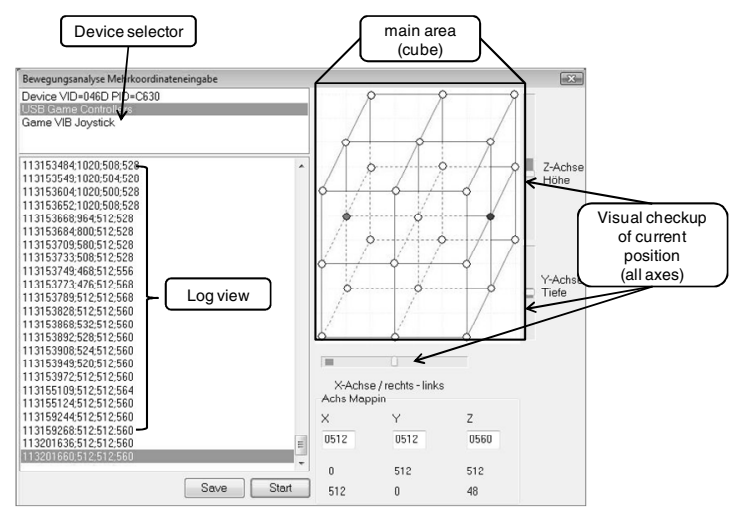

Fig. 4. Test Software

To support the experimentees during the tests, esp. to use the Haptor without other possibilities to control the spatial position, additional visual checkups were added on the right and bottom side of the main area.

Table 1. Description of subtasks

\begin{tabular}{|c|c|c|c|}
\hline & No. of subtask & $\begin{array}{c}\text { Starting point } \\
(\mathbf{x} ; \mathbf{y} ; \mathbf{z})\end{array}$ & $\begin{array}{c}\text { Goal } \\
(x ; y ; z)\end{array}$ \\
\hline$\rho^{\mathrm{PS}}$ & 0 & Undef. & P1 \\
\hline & & Undef. & $(512 ; 0 ; 512)$ \\
\hline & 1 & $\begin{array}{c}\text { P1 } \\
(512 \cdot 0 \cdot 512)\end{array}$ & $\begin{array}{c}\text { P2 } \\
(512 \cdot 1024: 512)\end{array}$ \\
\hline & 2 & P2 & P3 \\
\hline & 2 & $(512 ; 1024 ; 512)$ & $(1024 ; 512 ; 512)$ \\
\hline & 3 & $\mathrm{P3}$ & $\mathrm{P} 4$ \\
\hline & & $(1024 ; 512 ; 512)$ & $(0 ; 512 ; 512)$ \\
\hline $\mathrm{O}_{\mathrm{p}_{1}}$ & 4 & P4 & P5 \\
\hline & & $(0 ; 512 ; 512)$ & $(0 ; 1024 ; 1024)$ \\
\hline & 5 & $\frac{P 5}{(0 \cdot 1024: 1024)}$ & 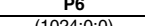 \\
\hline $\mathrm{p} 7 \mathrm{O}$ & & P6 & $\frac{(10<4,0,0)}{P 7}$ \\
\hline \multirow{5}{*}{ Fig. 5} & 6 & $(1024 ; 0 ; 0)$ & $(0 ; 0 ; 0)$ \\
\hline & & P7 & P8 \\
\hline & 7 & $(0 ; 0 ; 0)$ & $(1024 ; 1024 ; 1024)$ \\
\hline & 8 & P8 & P9 \\
\hline & 8 & $(1024 ; 1024 ; 1024)$ & $(512 ; 512 ; 512)$ \\
\hline
\end{tabular}

Due to hard- and software specificities not all input devices could reach the maximum of 1024 increments as well as the minimum of zero increments, according to the pixels of the cube shown. It was necessary to create an area of about 60 increments (depending on the type of input device) as a trapping area around the goal, which was accepted as "goal reached".

\subsection{Characterization of Experimentees (Test Subjects)}

The tests were performed with 19 attendees (14 male, 5 female) with a mean age of 23.5 years (range 19 from to 30 years). Two of the attendees are left-handed (but this was not considered as a co-factor). All of them stated that they were in good physical condition without any discomfort or diseases of neck-shoulder-arm-hand system. The anthropometric data of the attendees were measured three times each, as well before 
and after the tests. The anthropometric data measured were tested for normal distribution and statistical deviations to the control data of DIN [8] and [9].

Because the attendees were a highly selected group (students) they could not match the means of the German overall population. Standard t-test confirmed significant differences $(\mathrm{p}<0.05)$.

\subsection{Experimental Chain}

Each test started with an explanation of the whole experiment to the attendees, and a short training period with each input device, if necessary. Afterwards the first two measurements of anthropometric data were conducted. After this 22 IR-reflecting spherical markers were fixed at shoulder and arms like described in [10]. Additional five markers were fixed at each hand (shown in fig. 5), and three markers at the head (both temples and chin, see fig. 6). The points to fix the markers were palpated, but the markers could not be applied at bare bodies of attendees because of the low temperature.

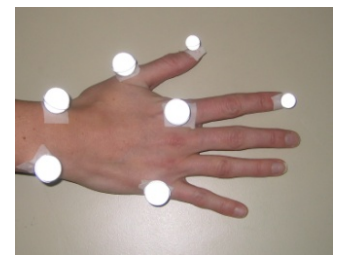

Fig. 5. Position of the hand markers

The investigator started the test software and the motion capturing system for the first run, the order of devices was: joystick, gamepad, Haptor. After this run the test person had to perform some physical actions (static: hold a weight of $2.5 \mathrm{~kg}$ in each hand; dynamic: squeeze a spring dumb-ball with a compression force of $100 \mathrm{~N}$ by each hand). Then the whole test was repeated. The second test additionally has been videotaped.

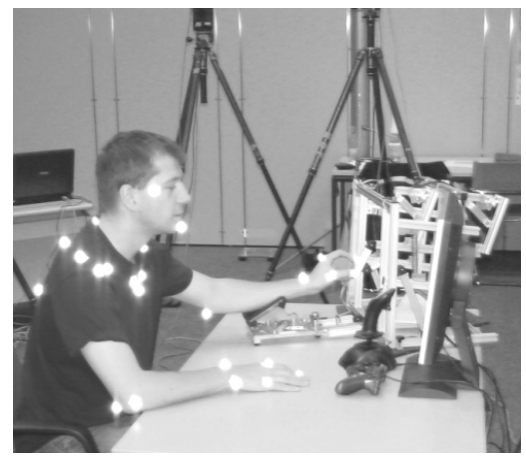

Fig. 6. An experimentee performing the test (with Haptor) 


\subsection{Aims, Hypotheses and Methods}

With the experiment described at first we simply but necessarily tried to test whether a motion capturing system with passive IR-markers is appropriate to investigate motions occurring during the use of $3 \mathrm{D}$ input devices. A second aim was to investigate the usefulness of different input devices for 3D input tasks by the use of standardized tests.

The hypotheses for the first experimental stage were:

1. For each input device different patterns are detectable and characterizable.

2. Due to the different design of the devices investigated the duration and the time to execute discrete parts of the tests differ.

3. Individuals have different motion patterns, but remodeled by the device used.

4. These patterns also depend on the grade of experience with such devices.

5. The patterns change after a provoked fatigue.

To test the hypotheses motion capturing system $(Q T M)$ data were collected and conditioned. Synchronously log-file data were recorded and also conditioned, especially adequately scaled to $Q T M$ data. Afterwards relevant $Q T M$ data (data of markers at the elbow, wrist, fingers, acromium and vertebra $C 7$ ) were filtered and their specific velocities and accelerations were calculated (by MATLAB routines with algorithms taken from [11]). All data chosen were tested with statistic standard methods.(by SPSS).

\section{Results}

\subsection{Analyses of Hardware Log-Files}

Haptor shows up to be the slowest input device (as well what concerns point-to-point as overall duration of task) shown in fig. 7, but on the other hand deviations between demanded and realized trajectories are lower than in the two other devices, as long as real 3D-movements (including a z-component like in subtasks four to seven like shown in fig. 8) are on demand.

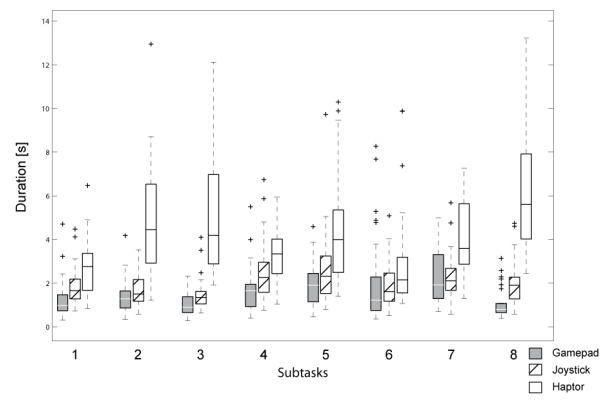

Fig. 7. Comparison of subtask duration of all input devices 


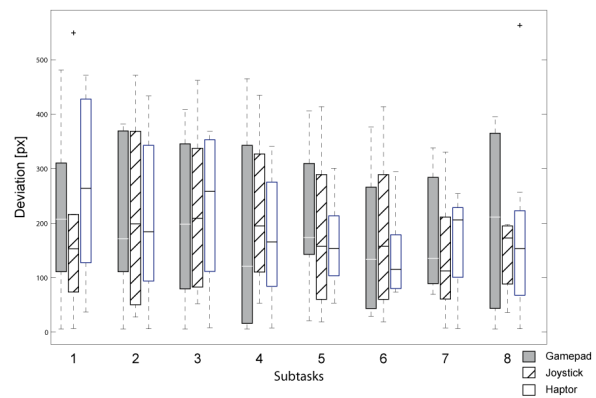

Fig. 8. Comparison of subtask deviations of all investigated devices

\subsection{Analyses of QTM ${ }^{\circledR}$-Data}

In all trials, no significant motion of the upper body (represented by marker C7) could be observed. Observable kinematics were restricted to hand-arm-system.

Vice versa mobility was realized by giving up fixation of wrist, in extreme visible in case of Haptor, where the lift of the arm from the hand rest is represented by lift of elbow and extension of wrist joint (cf. fig. 9). All attendees used hand rest had also negative values of lifting but a smaller range of wrist joint angle than attendees which are had not used the rest. The extension of wrist joint were significantly lower at attendees which are had not used the rest.

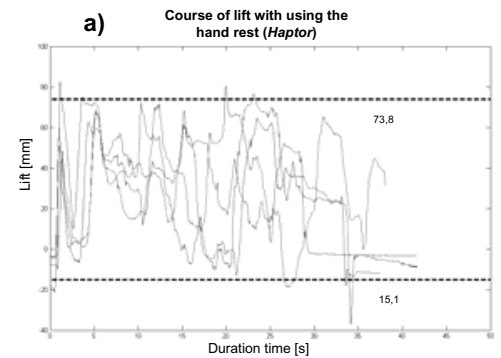

b) Course of lift without using

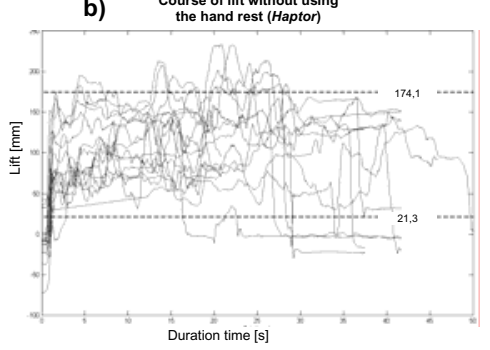

C) Comparison of resulting joint angle of wrist

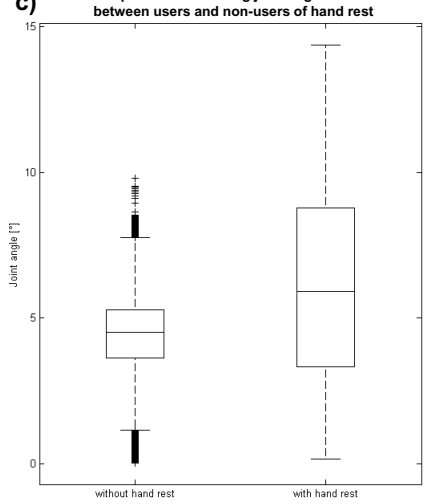

Fig. 9. (a) Lift of attendees using the hand rest, (b) Lift of attendees not using the hand rest, (c) Comparison of resulting wrist joint angle of both 


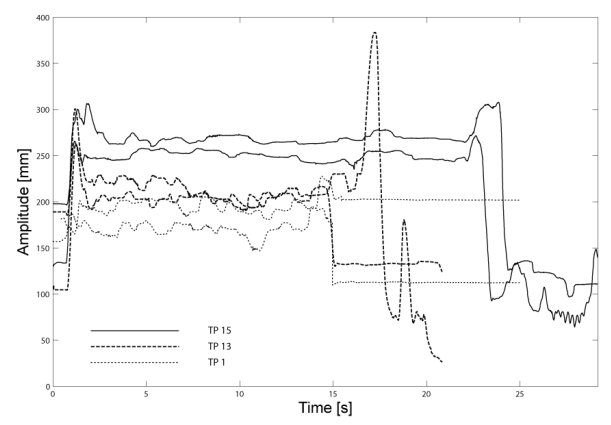

Fig. 10. Intra-individual patterns of three experimentees at a gamepad (right thumb, x-component $Q T M$ data)

Intra-individual patterns of kinematics did not occur systematically, but were observable in a subset of experimentees (fig. 10).

Another pattern could be abstracted: In case of gamepad, experienced users ("gamers") keep contact to the mini-joysticks only during "action", as long as a position is intended to be kept thumbs are lifted (fig. 11). This is represented by peaks which are correlated with reversal points of the logged input action.

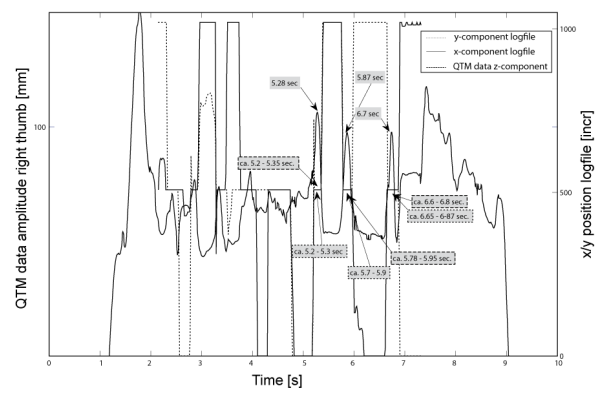

Fig. 11. Effect of thumb lifting at an experienced gamepad user

No effects of fatigue could be shown.

\section{Discussion}

The missing observation of fatigue effects indicates that our "loading" of experimentees was too low - obviously today usage of computer mice provokes a general training effect on endurance of hand-arm-system.

None of the devices analyzed provided observable inter-individual patterns. The occurrence of intra-individual patterns in subsets of the experiments indicates the adaptivity of users to devices - primary goal of ergonomics is the adaptation of devices to the physiology (and thus needs) of users. 
From our bionic synthesis of manipulative robots we know, that human grasping (and as well pointing) at minimum is composed of two atavistic factors:

1. reaching, performed by long elements (lower arm, upper arm, scapula),

2. grasping sensu strictu, performed by the hand

Both functions in the multifunctional human hand-arm-systems are adapted to a variety of yet not completely identifiable, partly diverging tasks, leading to compromises in structure and control. To mirror that nature given boundaries into human-machineinterfaces in future more intensely has to be based on function-morphological knowledge on reaching and grasping. Thus in our experiments in the next steps we shall focus on human and primate biology incl. handiness more than on technical devices.

\section{References}

1. Nowack, T., Kurtz, P., Lutherdt, S.: Ergonomische Gestaltung eines 3D-Eingabegerätes und Evaluation des Bedienkomforts. (Ergonomic design of a 3D-input device and evaluation of operational comfort. Only in German) In: Technische Universität (Hg.): Arbeitsgestaltung für KMU. Ilmenau: ISLE (Herbstkonferenz der Gesellschaft für Arbeitswissenschaft e.V.), pp. S.249-S.256 (2008)

2. DIN ISO 9241-410: Ergonomie der Mensch-System-Interaktion - Teil 410: Gestaltungskriterien für physikalische Eingabegeräte. DIN e. V. Berlin, Beuth (2008)

3. Keller Chandra, S., Hoehne-Hückstädt, U., Ellegast, R.: BGIA- Report 3/2008. Ergonomische Anforderungen an Eingabemittel für Geräte der Informationstechnik. BGIA- Institut für Arbeitsschutz der Deutschen Gesetzlichen Unfallversicherungen, Sankt Augustin (2008)

4. Krauss, L.: Entwicklung und Evaluation einer Methodik zur Untersuchung von Interaktionsgeräten für Maschinen- und Prozessbediensysteme mit grafischen Benutzungsoberflächen. Universität Kaiserslautern, Diss. (2003)

5. Nowack, T., Lutherdt, S., Gramsch, T., Kurtz, P.: An Evaluation Study for a 3D Input Device Based on Ergonomic Design Criteria. In: Dainoff, M.J. (ed.) HCII 2007 and EHAWC 2007. LNCS, vol. 4566, pp. 257-266. Springer, Heidelberg (2007)

6. Nowack, T., Kurtz, P., Lutherdt, S., Gramsch, T., et al.: Design of an Evaluation Study for 3D Input Devices. In: Proc. of the $9^{\text {th }}$ ERCIM Workshop User Interfaces For All (UI4All), Königswinter (2006)

7. Nowack, T.F., Kurtz, P., Gramsch, T., Lutherdt, S., Schäfer, S.: Ergonomisch motiviertes 3D-Eingabegerät - "Haptor". In: Restorff, W.v. (ed.) Forum Arbeitsphysiologie 10. Symposium Arbeitsphysiologie für Nachwuchswissenschaftler, München, p. S20 (2006)

8. DIN 33402-2: Ergonomie - Körpermaße des Menschen - Teil 2: Werte. Deutsches Institut für Normung e. V.Berlin, Beuth Verlag GmbH (2005)

9. Flügel, B., Greil, H., Sommer, K.: Anthropolog. Atlas. Frankfurt/M. Edition Wötzel (1986)

10. Wu, G., van der Helm, F.C., Veeger, H.E., Makhsous, M., Van Roy, P., Anglin, C., Nagels, J., Karduna, A.R., McQuade, K., Wang, X., Werner, F.W., Buchholz, B.: ISB recommendation on definitions of joint coordinate systems of various joints for the reporting of human joint motion-Part II: shoulder, elbow, wrist and hand. J. Biomech. 38, Seite, 981-992 (2005)

11. Andrada, E.: A new model of the human trunk mechanics in walking. In: Berichte aus der Biomechatronik. Witte, H. (Hs.) Fachgebiet Biomechatronik an der TU Ilmenau Band 1, Ilmenau, Universitätsverlag (2008) 